\title{
Two-Sided Platform Ecosystems' Structure, Architecture and Mechanism: an Integrated View--Under the Background of Industry 4.0
}

\author{
ZHENG SHENG HUA, BADER TARIQ EID HAKAM, AGBANYO GEORGE KWAME*
}

School of Management, Zhejiang University of Technology, Hangzhou, Zhejiang, P.R.China

*Corresponding Author.

\begin{abstract}
Platform model is one of the most prominent phenomena in modern business with the development of the Internet and the continuous expansion of the scale of industry 4.0 related industries. Two-sided platforms show features whereby two groups of agents interact with each other, in order to promote resource exchange and value creation. This review presents an integrated framework for understanding key factors of platform ecosystems, analyzing its member structure and technology architecture, exploring the dynamic mechanism and competition mechanism. Platform ecosystems refer to the core platform and its cooperative network of stakeholders, mainly consist of providers, sponsors, complementors and end users. The dynamic mechanism and competition mechanism are mainly in the realization of network effects and "winner-take-all". These bring some management challenges, the preventive strategies are embodied in platform pricing, positioning, binding, in realization of ecosystem expansion and multi-win situation, to face the "egg-and chicken" syndrome and "get both sides of the market onboard". Using this foundation, this research finally proposes five directions for future research in these settings, including the influence of platform technology architecture on complement or innovation, profit model of platform companies, environmental factors in platform competition, new challenge of platform envelopment and dynamic research methods, hoping to offer substantial new insights in the context of platforms and ecosystems.
\end{abstract}

Keywords: Platform model, Internet ecosystem, Business environment, Industry 4.0

\section{Introduction}

In the light of the global radically changing business environment, especially the rapid development of the Internet and mobile technology, many companies have achieved great success with the concept of the platform model, such as Amazon, Google and Taobao. While the platform is often associated with the Internet, the platform strategy is actually applicable to many industries in reality as with bank cards, telecommunications, retail, media and many other industries, which are all involved in platform model. In addition, some traditional businesses have been reconceived as platforms. Managers in strategic and innovative organizations are increasingly faced with competitive challenges in complex technology situations. Retail electricity markets, for example, are evolving into platforms that connect consumers with specific power producers, introducing and utilizing external expertise and resources to connect consumers and suppliers, allowing them to express their preferences for less expensive coal or more expensive renewable power.

These companies and industries have similar features and laws. They rely on platforms to meet the needs of two different types of users, mediate these users' interaction and facilitate their transactions in order to achieve their own value and make profits. Because platform providers must satisfy both the demand and supply sides of the customers, these platform-based markets are frequently referred to as two-sided markets, who are called end users and complementors on board. This kind of platform is what we call the two-sided platform. It is noted that some platforms are single-sided or multi-sided, which have one group or three or more distinct groups of users. These kinds of platform are not within our scope, in this research the two-sided platform is the only model discussed.

The concept of platform ecosystems belongs to the scope of commercial ecosystems. Platform ecosystems refer to

ISSN: 0010-8189

(C) CONVERTER 2020 
the platform and its cooperative network of stakeholders. Providers, sponsors, complementors and end users form the core part. Most of the literature in network economics and platform theory holds a similar view to the target positioning of two-sided platforms ecosystems, "Two-sided platform ecosystems facilitate transactions between two distinct groups of customers, who depend on each other to achieve their own viability and effectiveness. "Platform's ecosystems bring together different types of participants, coordinate the interactions between them, in order to promote resource exchange and value creation" ${ }^{[7]}$. However, there has been a lack of clear description and comprehensive understanding on two-sided platform ecosystems in existing literature, so it is necessary to make an in-depth exploration and further exposition.

Platform ecosystems' dynamics mechanism and competition mechanism, different from the traditional vertical competition, are mainly in the realization of network effects and "winner-take-all". Combined with the network effects, the two-sided platforms can accumulate a large number of user base, occupy the vast majority of the user share in the market, which brings the platforms the super power of "winner-take-all" and the nature of creativity destruction. Platform model belongs to the high-end industry chain, due to the industrial integration, the winner is increasingly easy to control industrial incomes, stimulate the network effects, break through the tipping point and eventually achieve the market absolute competitive advantage.

Such mechanisms present some unique challenges in their management strategies. From the previous research point of view, most of the literature on the platform strategies are about one aspect of the core platform company behaviors. But actually, the management strategies are holistic and systematic. A possible market entry fee from each seller and buyer compensates the platforms for their services (though in almost all cases, the platforms choose not to charge the latter group), and the platforms are compensated for their services by a possible market entry fee from each seller and buyer (though in almost all cases, the platforms choose not to charge the latter group), and the platforms are compensated for their services by choosing dominant position or market followers according to their distance of their offerings. For existing users, the platforms need to increase their conversion costs to bind this part of the users; for users who have not yet joined, platforms achieve the infinite expansion through mechanism construction of values and functions, and ultimately reach multi-win situation in each link of the ecosystems.

This research note summarizes the existing literature contributions and systematically analyzes the key factors of platform business model-platform ecosystems. The former part conducts an integrated combing on platform definition, features and categories, making an in-depth study of the platform ecosystem internal structure, exploring the interaction network effects and the "winner-take-all" competition mechanism, followed by the strategies proposed to enhance capabilities on managing platforms ecosystems and companies, which explains the "egg-and chicken" syndrome and "get both sides of the market onboard" from the perspective of platform ecosystems. The latter section discusses several fields of future consideration that present significant research opportunities. The final section concludes. We argue that, the platforms are always in a relatively stable but constantly evolving state, a successful two-sided platform is not just a simple channel or intermediary, the key of platform business model is to create a strongly potential ecosystem, encouraging the interaction of two groups through sophisticated architecture and network mechanisms to establish the "virtuous circle", developing appropriate strategies in each link to deal with fierce market competition ${ }^{[11]}$. Ultimately achieve the goal of value creation of each side of groups and platform companies, meanwhile dismantling the status quo of the industry and reshaping the market structures in a new way.

By addressing the subject about these issues, we hope for better building multi-win ecosystems in platform model and guiding platform to participate competition in platform market. As the increasingly important role played by the platforms and networks in a great of environments, it is a key research pathway to understand the core factors and results of platform ecosystems for scholars and practitioners.

\section{Platforms}




\subsection{Platform definition}

Wheelwright and Clark first proposed the concept of platform, pointing out that platforms are the products that meet the needs of the core consumer groups, which are designed to be easily improved for derivatives by adding, replacing, or eliminating features of certain parts. Following that, the concept of platforms was continuously developed within three academic literature streams originating from different perspectives: technology management, strategy management, and network management (see table 1).

From the technology management point of view, it emphasizes the technical feature of the platforms as a basis for other functions and for the related products or services which companies can conduct ${ }^{[13,14]}$. This stream describes the platforms as space where platform sponsors and third-party complementors seek possible innovation ${ }^{[15]}$

By contrast, the emergence and sustainability of competitive advantages and strategies in competition situations are paid close attention by strategic scholars. Platform companies get competitive advantage if they provide greater value to users at a lower investment than competitors ${ }^{[16-18]}$. This advantage strongly demands the platform companies to foster the capabilities of build their complementary networks to stimulate the value of co-creation. As a result, strategic management studies have interests on strategic synergies with third parties and platform leadership.

Network management researchers are of the view that the management of a platform needs to expand the scale of this network and coordinate these network relationships. Complements appreciate the quality of a core good to users via network effects. In all, platforms can be as products or services that connect different types of users. Platforms are essentially products, technology or services, not companies nor any organizational structure. The field of platform has been explored in many studies concerning the notion of marketing, software engineering, economics drawing groups of users together in two-sided networks, information systems.

\subsection{Platform features}

The platforms are multi-level complex systems, always in a relatively stable but constantly evolving state. The platforms have the following four structure features:

First, the platforms have cooperativity. As economic systems, the evolution of platform will lead to the synergies and symbiotic relationships between relevant groups. In a platform, the elements are not a simple combination, each member must be clear about their own niches, paying attention to communication and fitness with other groups. The complementary companies rely on platform companies to conduct asset-specific high investment, further improving the products or services of platform companies. The main bodies achieve functional complementarity in the co-actions with each other, promote platform evolution in the collaborative interactions, leading to the material flows and the information flows operate smoothly, eventually meeting the requirements of the cycle development, reaching the adaption with the surrounding environments, and obtaining the effect that the overall function of the platform greater than the sum of the part functions. Second, the platforms have diversity. Diversity refers to the multiple categories of the main bodies and the varieties of business activities. The diversity of platforms means that the flows and transmission channels of energy, material, and information between the groups are diversified, the control skill is strong, the metabolism function is sound, the diversified structure is maintained with higher levels, which are beneficial to improving the sustainability of the platforms and achieving the coevolution in the platforms.

Third, the platforms have ductility. A large number of humans, physical, financial and information exchange inside and outside the platforms, forming viable, increasingly developed dissipative structural economic systems. It can be said that platform ductility is the basis of constantly attracting external capital, technology, information and other resources to evolve and grow. Platforms are not closed and self-running systems, their ductility determines

ISSN: 0010-8189 
their powerful embeddedness and scalability. Fourth, the platforms have stability. The network structure of the platforms is complex and intensive. Platforms are relatively stable in structures and functions. The overall system will not collapse when a single group is absent, which form the stability features of the platforms. These stability and balance features can be maintained by self-regulation. At the same time, external material, energy and information changes make the relationships unbalanced, which promote the platforms to constantly evolve and grow, to further reinforce this stability.

\subsection{Platform category}

According to the former theory, platforms can be categorized in four ways, based on: i.)Platform competition degree; ii. )Platform control structure; iii.)Platform function; and iv. )Number of user groups.

i. Degree of platform competition

Armstrong categories platforms from the perspective of competition degree. He divides the market into three kinds of platforms. First is the monopoly platform, in which there has only one platform in the market; Second, the competitive platform. Both sides have a number of platforms to choose from, but each side still has a single ownership, that is, participants of each side can choose only one platform to trade; Third, the platform which has a competitive bottleneck, that is, both sides want to join all the platforms, which form a "multi-channel" or "multi-attribution" situation ${ }^{[23]}$.

\section{ii. Structure of platform control}

Platforms can be divided into open platforms and proprietary platforms according to their control structure. Open platforms mean that the access to the platforms is open and standardized, as that the Linux operating system platform opens. The openness of the platforms means that the platform owners open platform technologies, effectively reducing the access, use and commercialization restrictions. Proprietary platforms refer to the control of their own technical standards and the limitation of the source code development. One or more platform sponsors own and control these types of platforms entirely. Their proprietary technology is not compatible with third-party components and is protected by legal intellectual property rights. Open platforms, on the other hand, are not protected by intellectual property laws. By making technology available to the general public, they automatically relinquish ownership and control.

\section{iii. Platform function}

Rochet and Tirole argue that there are price regulating platforms, licensing authority platforms and competition governance platforms classified according to the difference of functions. We divide the platforms into four categories - transfer platforms, variety platforms, searching platforms and pricing platforms. Transfer platforms share information, goods, or passengers between two parties or locations, such as email, communication platform and package delivery, sender and receiver alternate roles based on the circumstances.

\section{iv. Number of user groups}

Platforms are classified based on the number of unique user groups they support. Single-sided platforms feature homogeneous users, as opposed to two-sided platforms, which have two distinct user groups whose members regularly perform the same function in transactions. Each group's members have a choice for the quantity of users in other groups. Some media platforms, for example, connect three types of network users: content consumers, third-party content creators, and marketers (e.g., YouTube).

\section{Two-sided platforms}

Two-sided platform is formally proposed by Rochet and Tirole, originated in the network economics, its source comes from the scholars' concerns and research on the two-sided matching systems. They connect buyers and sellers, who are called demand-side users and supply-side users, relying on platforms for interaction and

ISSN: 0010-8189 
transaction. Table 2 provides some examples in two-sided markets. Wang distinguishes two-sided markets from the three following aspects: 1) whether the two sides of the transaction are in indirect contacts. In the traditional single-sided markets, buyers and sellers are in direct contacts. In the two-sided markets, the two sides of the transaction are not in direct contact; 2) whether the two sides interact on the same platforms. In the two-sided markets, there must be a sufficient number of users on both sides of the platforms, although they can choose one or more platforms, but the implementation of the transactions between them must be completed on the same shared platforms; 3) whether the supply and demand relationships on two sides are indirectly affected by the number of each other. The impact between the buyers and sellers in two-sided markets is indirect, which is commonly referred to as indirect network externality.

Table 1: Selected studies on platform definition

\begin{tabular}{|c|c|c|c|}
\hline Perspective & Author & $\begin{array}{l}\text { Research } \\
\text { dimension }\end{array}$ & Research content \\
\hline \multirow{4}{*}{$\begin{array}{l}\text { Technology } \\
\text { management }\end{array}$} & $\begin{array}{l}\text { Tiwana, } \\
\text { Konsynski } \\
\text { Bush,2010 }\end{array}$ & Platform design & $\begin{array}{l}\text { Development of common evolution } \\
\text { framework model and evolution } \\
\text { dynamics of platform design and } \\
\text { governance }\end{array}$ \\
\hline & $\begin{array}{l}\text { Eisenmann, } \\
\text { Parker \& Van } \\
\text { Alstyne, } 2009\end{array}$ & Open degree & $\begin{array}{l}\text { Factors that affect platform opening } \\
\text { and closing }\end{array}$ \\
\hline & $\begin{array}{l}\text { Fuentelsaz, } \\
\text { Garrido \& } \\
\text { Maicas, } 2015\end{array}$ & $\begin{array}{l}\text { Third-party } \\
\text { supplement }\end{array}$ & $\begin{array}{l}\text { The value of complementary assets } \\
\text { to incumbents after a technological } \\
\text { change varies according to } \\
\text { contextual factors }\end{array}$ \\
\hline & Gawer, 2009 & $\begin{array}{l}\text { Modular } \\
\text { architecture }\end{array}$ & $\begin{array}{l}\text { The importance of modular } \\
\text { architecture to inspiring partner } \\
\text { products, technology and service } \\
\text { innovation }\end{array}$ \\
\hline \multirow{4}{*}{$\begin{array}{l}\text { Strategy } \\
\text { management }\end{array}$} & Liang, 2008 & Pricing strategy & $\begin{array}{l}\text { Pricing of B2B e-commerce platform } \\
\text { from the perspective of two-sided } \\
\text { markets }\end{array}$ \\
\hline & $\begin{array}{l}\text { Gawer } \\
\text { Cusumano, } \\
2008\end{array}$ & $\begin{array}{l}\text { Platform } \\
\text { leadership }\end{array}$ & $\begin{array}{l}\text { The impact of the four aspects of } \\
\text { leadership to the platform }\end{array}$ \\
\hline & $\begin{array}{l}\text { Sheremata, } \\
2004\end{array}$ & $\begin{array}{l}\text { Competition } \\
\text { advantage }\end{array}$ & $\begin{array}{l}\text { The challenge to the large incumbent } \\
\text { from smaller participants in platform } \\
\text { market }\end{array}$ \\
\hline & Berzosa, 2012 & Value creation & $\begin{array}{l}\text { Value creation of platform mediated } \\
\text { networks in mobile industry }\end{array}$ \\
\hline \multirow{3}{*}{$\begin{array}{l}\text { Network } \\
\text { management }\end{array}$} & $\begin{array}{l}\mathrm{Li} \quad \text { \&Wang, } \\
2016\end{array}$ & Network effects & $\begin{array}{l}\text { Platform network effect and cross - } \\
\text { platform network effect mechanism }\end{array}$ \\
\hline & $\begin{array}{l}\text { Venkatraman \& } \\
\text { Lee, } 2004\end{array}$ & $\begin{array}{l}\text { Network } \\
\text { structure }\end{array}$ & $\begin{array}{l}\text { Platform network structure and } \\
\text { features }\end{array}$ \\
\hline & Du\&Chu, 2017 & $\begin{array}{l}\text { Network } \\
\text { management }\end{array}$ & $\begin{array}{lcl}\text { Platform } & \text { network } & \text { dynamic } \\
\text { mechanism and complex } & \text { platform }\end{array}$ \\
\hline
\end{tabular}

ISSN: 0010-8189 
In two-sided markets, there are strong interaction and dependency between the two groups, which requires two-sided platforms to coordinate. The success of the two-sided platform is determined by the number of members it can recruit from both sides, as well as the interaction effects between them. Each group's members have a preference for the number of users in another group, and they can also have a choice for the number of users in their own. The two different groups of users can create value through direct interaction between same type of users and get more value from participants of another type. The two-sided markets constructed by the platforms are quite different from the traditional single-sided markets, mainly reflected in the network effects which can make use of two-sided relations to establish the possibility of unlimited value-added. Choi argues that the determinate nature of the two-sided platforms is that one side of the users' benefits depend on the number of other side of users, as with Facebook, which connects applications providers and network users; and music platforms iTunes, which links digital media manufacturers to consumers. The role of platform companies is that they have the foundational technologies that support a complementary third-party innovation. They offer the two groups intermediary services, mediate interactions between buyers and sellers by exploiting network effects and providing strucutres and guidelines that facilitate their transactions and can take many guises. In this business model, platform companies connect two specific sides that offer an interactive mechanism to meet the needs of both, and skillfully getting profits from it.

Table 2: Examples of platform-based markets

\begin{tabular}{llll}
\hline Market & Side 1 & Platforms & Side 2 \\
\hline PC operating systems & Computer users & Windows, Macintosh & Application developers \\
Web browsers & Internet surfers & Internet Explorer, Firefox & Plugin developers \\
Portable documents & Document readers & Adobe & Document writers \\
Online marketing & Buyers & eBay, Taobao & Sellers \\
Video sharing & Clip makers & YouTube, Youku & Clip watchers \\
Online dating clubs & Men & American Singles.com & Women \\
Credit cards & Card holders & Visa, Union Pay & Merchants \\
Stock trading & Stock buyers & NASDAQ, SHSE & Listed companies \\
Video games & Game players & Xbox, PlayStation, Wii & Game developers \\
Recruitment sites & Job seekers & Monster.com, 51job & Employers \\
\hline
\end{tabular}

Source: Related information.

\section{Two-sided platform ecosystems}

\subsection{Member structure}

Zahra and Nambisan view commercial ecosystems as networks which are built by different companies based on strategic cooperation relations. They provide the necessary collaborators, resources and information for these companies. Platform ecosystems refer to the complex systems of interrelationship, mutual cooperation and common evolution formed in the platform activities by constant communications and interactions between ecological subjects or between the subjects and the external environments.

Iansiti and Levien divide a commercial ecosystem into the key companies, niche companies and consumers. The key companies provide a setting in the forms of services, technology or tools. The niche companies provide a variety of specialized services and products to the ultimate consumer. Where the key companies are the platform providers, the niche companies are equivalent to the supply-side users and the consumers are equivalent to the demand-side users. Gawer make the platform ecosystems divides into the core members and the complementary members. The core members provide key resources and technologies as a platform support, and the complementary members play the role of synergy. Based on the above theories, this paper divides the platform ecosystems into

ISSN: 0010-8189 
three categories: leadership groups, key groups and support groups. Leadership groups include the core platform providers and platform sponsors, which are the leaders and managers of the whole ecosystems, providing shared platforms and technology subjects. Key groups refer to the main trading entities of the platforms, including consumers, retailers, professional suppliers, supplement providers for value-added services. They are "customers" that jointly serviced by the platforms. Support groups are attached organizations in the platform transactions, including financial institutions, logistics companies, government agencies, and so on. Leading groups and key groups are the main components of the core ecosystems, and the support groups are the main components of the peripheral ecosystems. In two-sided platforms, we can say that the platform providers, the platform sponsors, the end users and the complementary providers having the cooperation relationship form the platform core ecosystems, constituting the main behavior bodies of the two-sided platforms, having the greatest impact on the platform ecosystem value networks (see figure 1).

Every two-sided platform is to offer two specific different roles: platform providers and platform sponsors. Platform providers occupy the critical hubs and have a decisive impact on the evolution of platform ecosystems. They are entities that intermediate platform users' interactions, serving as their focal points of contact with a platform. Platform sponsors on the other hand are the controllers of platforms. They do not deal directly with users but design components and rules, holding clear rights to specify platform participation and technology modification. For example, MasterCard, which owns the payment system's technology, is the platform sponsor, while Citibank, who runs the payment system using MasterCard technology, is the platform provider. However, as in the instance of American Express, both responsibilities might be fulfilled by the same business.

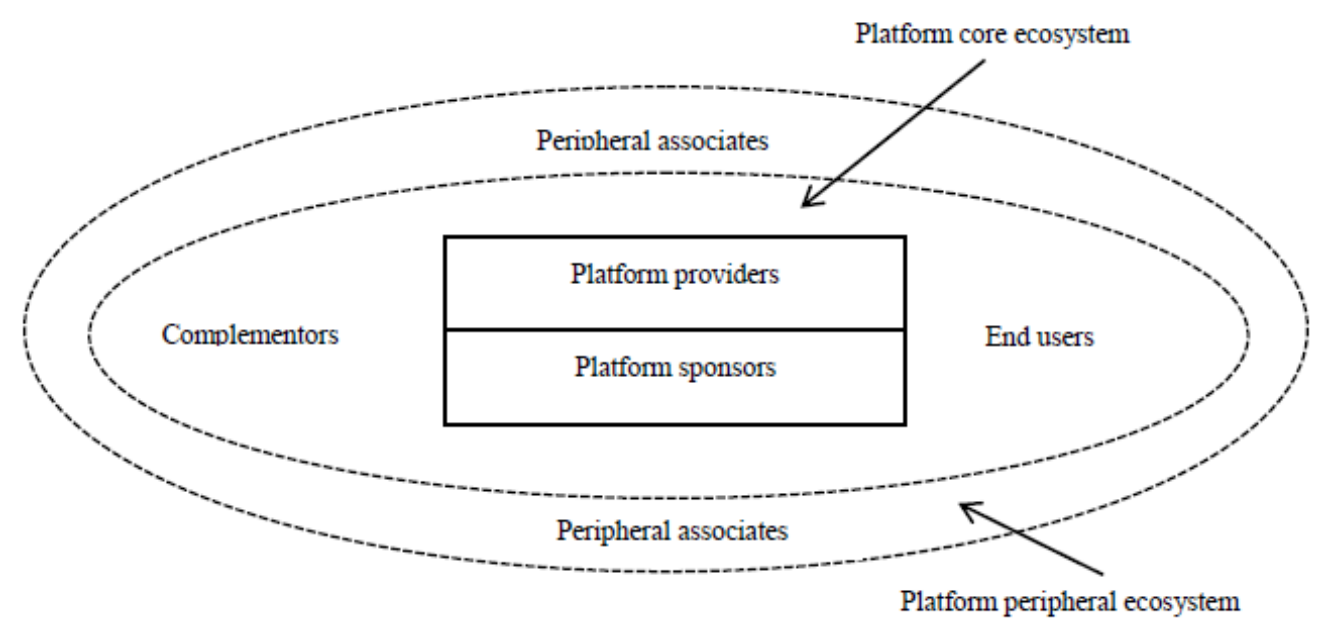

Figure 1: The member structure of platform ecosystems.

The platform providers and the platform sponsors facilitate the transactions and interactions between complementors and end users or between the end users. End users refer to demand-side users, who get a variety of products or services from users on the other side or from platform directly. Demand of end users is for the overall system; they get many benefits from platforms and another side. Complementors refer to supply-side users, who offer essential products and services that are not directly provided by platform providers. In a two-sided platform, producers of complementary products on one side compete to sell to end users. Complementors are supply-side users who provide critical products and services that platform providers do not provide directly. On one side of a two-sided platform, complementary product producers compete to sell to end consumers. End users use the platform's primary features to engage in complementary involvement. Each of these jobs may be open or closed depending on the platform.

The platform peripheral ecosystems consist of peripheral associates, including financial institutions, trade 
associations, suppliers and other risk-takers, government departments and other quasi-governmental organizations that formulate regulations, as well as research institutes, other same kinds or different kinds of companies in ecosystems. They mainly provide support services for the platforms, improving the platform's living environments, and at the same tine take considerable benefits from an optimized ecosystem. These groups are not directly related to the platform operators, or have a direct and indirect relationship with the complements and competitors in the core systems. Therefore, we think that these members' overall impact on the platform ecosystems is small due to the lack of taking platforms as necessary relational mediums.

\subsection{Technology architecture}

Platforms use a common architecture to provide a value source. An ecosystem can be divided into a central platform system and complementary sets of module subsystems thanks to the conceptual specification of interfaces. Simon's early work on "complex systems," which are described as hierarchical and decomposable systems made up of interacting and interdependent subsystems, is the foundation for platform technology design. In the same way, platform technology architecture is the design logic of the overall system and its components, partitioned into hierarchically ordered core subsystems (the core platforms) and supplemental subsystems (the complementary modules) that are complementary to each other and connected through interfaces, as well as one or more intermediaries that facilitate communication between them. Table 3 is definitions of core concepts of platform ecosystem technology architecture, which includes the sets of modules, components, rules, and standards employed in common in most user transactions. The architectural decisions are long-term because a platform owner can be trapped into them for a long time.

Modules are add-on subsystems that connect to the platform to provide additional functionality. The number of subsystems into which a platform can be partitioned represents the platform's breadth (this "atomic" level is subjective). Modules refer to the deconstructed subsystems. Changes inside a subsystem do not have a rippling impact on the behavior of other portions of the ecosystem, according to modularity. As a result, in a highly integrated modular design, individual modules must be able to be changed without damaging their ability to work together again, which can be accomplished by improving module decoupling and standardizing platform-module interfaces.

Table 3: Definitions of core concepts of technology architecture

\begin{tabular}{|c|c|c|}
\hline Concept & Definition & Representative references \\
\hline Modules & $\begin{array}{l}\text { The add-on subsystems that connect to the } \\
\text { platform to add functionality to the platform }\end{array}$ & $\begin{array}{l}\text { Baldwin and Clark, 2000; } \\
\text { Sanchez and Mahoney, 1996; }\end{array}$ \\
\hline Components & $\begin{array}{l}\text { A setting can be separated and recombined, } \\
\text { including hardware, software, and service } \\
\text { modules }\end{array}$ & Henderson and Clark, 1990 \\
\hline Rules & $\begin{array}{l}\text { The design specifications used to coordinate } \\
\text { network participants' activities }\end{array}$ & Baldwin and Clark, 2000 \\
\hline Standards & $\begin{array}{l}\text { The technical specifications used to ensure } \\
\text { compatibility between architectures within } \\
\text { the ecosystem }\end{array}$ & $\begin{array}{l}\text { Suarez, 2005; } \\
\text { Eisenmann, } 2007\end{array}$ \\
\hline
\end{tabular}

\subsection{Competition mechanism}

The evolution of the platform ecosystem is a process of attracting bilateral users to join. The network effects affect the expected utility of the users into platform networks and then affect their willing to enter. The relationship between these factors and the expected utility of the users constitutes the internal dynamic mechanism of the platform ecosystem evolution. Network effects are also known as network externality, referring to the phenomenon

ISSN: 0010-8189 
that when the number of users of a product or service increases, their utility increases followed. Platform ecosystem network effects include same-side network effects, cross-side network effects and synergy network effects. The network effects trigger a positive feedback loop among the platform providers, complementors and the end users.

The platform business model has "winner-take-all" super power due to the network dynamics theory. The platform ecosystems with the largest number of users will have the most favorable market competition outcomes, and consumers create highest value on platforms with the largest number of users and complementors. The so-called "winner-take-all" (called WTA in the following) refers to the considerable gap between market's first and second place. Usually, the leader company will have forty to sixty percent or even more of the market share. Platform's ecosystems realize system design and market supply of related products and services based on resource integration, satisfy the fragmentation needs of consumers, and win all or most of the market share.

In most platform ecosystem markets; the combination of strong network effects and high destruction of creativity means there is only room for a few players. The entry barriers that allow two-sided platforms to earn high returns also make them difficult to build in the first place. Aspiring platform providers face big challenges when constructing a new ecosystem. The biggest challenge occurs when prospect users on each side are reluctant to invest in the platform until they are convinced of a reasonable number of users on the other side. Some see this as a "chicken-and-egg" situation. A party subject to this situation must undertake two actions that each depends on the other being completed first. For example, you cannot get a job without experience, and you cannot get experience without a job. Starting up a two-sided platform presents a similar quandary. According to the network effects and the competition effects, the evolution path of the platform ecosystems is shown in the following figure 2.

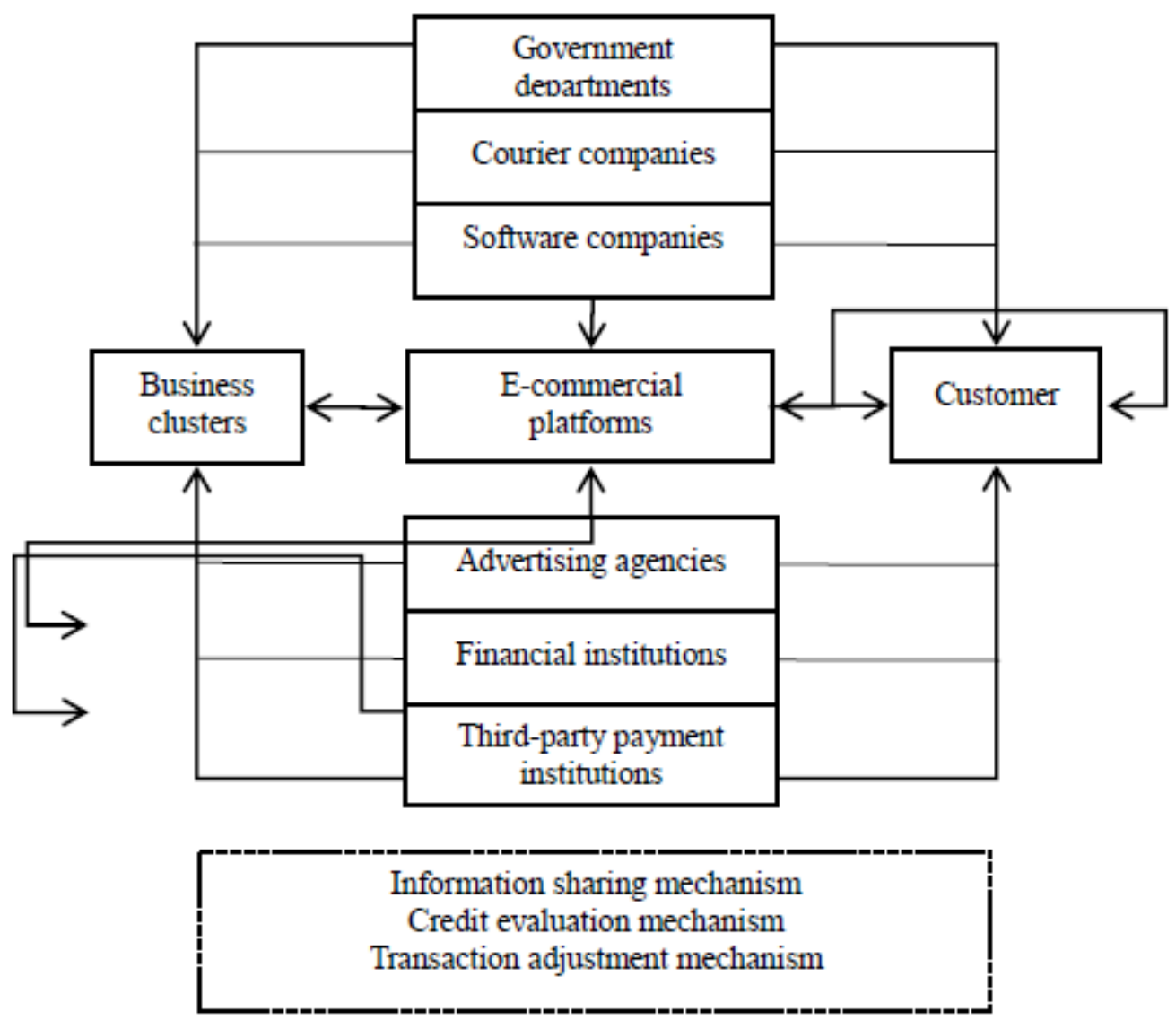

Figure 2: Principal members and network effects in e-commerce platforms

The possibility of WTA determines the degree of intension in platform competition. When developing entry tactics,

ISSN: 0010-8189 
it's critical to know whether a new platform market will be served by a few or perhaps a single monopoly platform or by competitor platforms. Put simply, competition in WTA markets is unforgiving: losers face extinction. If managers of aspiring platform providers conclude they will confront WTA market, they must make two decisions. First, should they enter the new market at all? Second, should they aim to maintain proprietary control over their platform or share it with competitors if they do enter? Platform firms would be compelled to: 1) swiftly acquire and build their platform's installed base of users; 2) lock in those users; and 3) impair competing platforms' capacity to achieve the same at this time if they pursued an aggressive strategy. In platform markets, the WTA outcomes are affected by following three factors.

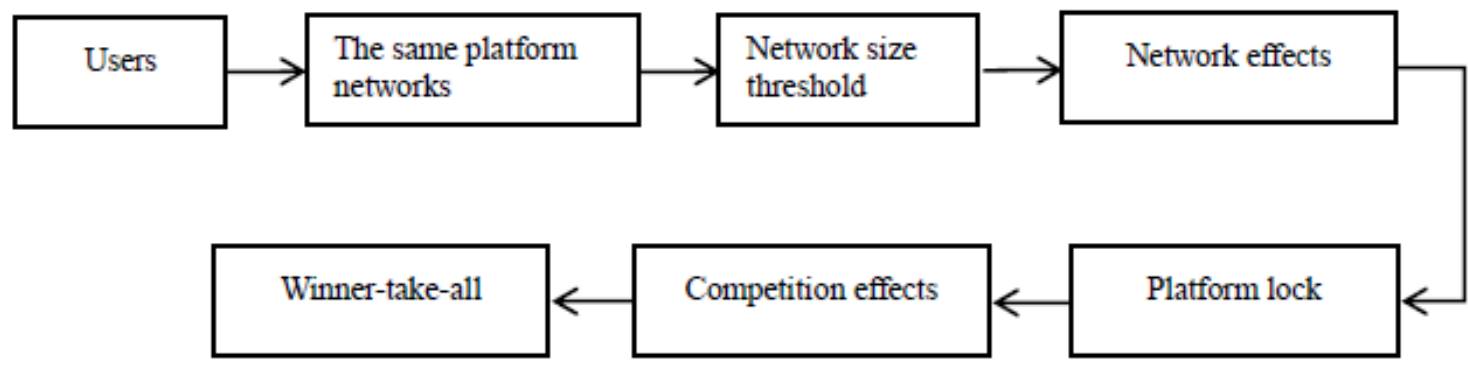

Figure 3: The evolution path of platform ecosystems

Some business with strong scale economies may exhibit increasing returns to scale. Some businesses exhibit constant returns to scale. The lowest level of output at which a firm's unit cost can be reduced is known as the minimum efficient scale (MES). In most industries, MES is modest in respect to the overall size of the mature market. But MES is relatively large in platform markets. When this is the case, there is not enough room for rivals. This may because the costs of efficiently extending business so great that the market can only support a single profitable player. This phenomenon is called natural monopoly. Many platform industries show the feature of natural monopoly including railroads, telephone systems, electric power system and postal delivery.

Conversion costs are the price users need to pay when leaving the current platform to join rivals' platforms. If it is expensive for platform users to contact with multiple platforms, they will be more willing to choose a single platform. Conversion cost can be grouped into upfront, ongoing, and termination costs, including platform-specific investments, out-of-pocket expenses, and inconveniences of users because of contact with a platform. Many of the costs listed are simply duplicated when a user participates in a second platform. However, the cost of converting multiple platforms is not always simply added. a user might realize some economies by contact with multiple platforms. For example, the time of searching for a second platform might be reduced.

\section{Two-sided platform management strategies}

\subsection{Platform pricing}

The development of optimal price structure is the key and difficult point of platform competition in two-sided markets. Platforms for two-sided networks can generate revenue from both sides of the network. Which side should you subsidize and which side should you charge? This is the crucial strategy question. Many studies explore the factors that influence pricing and price structure problem. Rochet and Tirole analyze the factors that affect the pricing of two-sided platforms, including demand elasticity of two-sided users, the market strength of different platforms, which side of users realize remaining, the competitive strategies adopted by platforms, and whether the platforms allow multiple attribution and bundling. Bakos and Katsamakas point out that the difference in external effects of two-sided users is a factor influencing the pricing structure and competitive strategies. Based on the study of two-sided B2B networks, they find that independent B2B platforms have been free of charge for the side of low yields, but raise fees to the side of potential high profits, thus get benefits. In addition, the same pricing strategy will exist only if the two-sided users bring the same external benefits to the platform.

ISSN: 0010-8189 


\subsection{Platform positioning}

Most platforms seek to mimic their competitors' content and application portfolios and compete hard for market share and platform supremacy in head-to-head conflicts. Platform leadership tactics, which include racing to capture the market by selecting the platform positioning that offers the most rapid development, are prevalent and significant, particularly in a WTA paradigm. There is no evidence that quickly occupying the market share can achieve the purpose of controlling platform industry. Many of the earlier platform companies cannot remain the leading market position, such as the bank card business, personal computer and notebook computer industry, as well as online trade portal.

In several contexts, there is a multiple platforms coexistance. Platforms may choose market positioning that is distinct from that of competitors in several situations. This entails constructing a platform environment that is distinct from that of competitors. This is referred to as distinctive positioning. Only when organizations enhance the gap between their offers in the competitive landscape can distinctive positioning be helpful. Otherwise, a platform that wants to deescalate conflict but opts for a middle ground risk failing to minimize competition while also failing to place itself in a market with sufficient demand. Offering a more similar selection of content and applications in an intermediate position would obscure the distinctions between platforms in the minds of users. Swaminathan indicates that distinctive positioning and platform performance have a U-shaped relationship. Only enterprises that pick high levels of distinctiveness have a chance to build a "genuine identity" in the market niches they service and become consumers' preferred option.
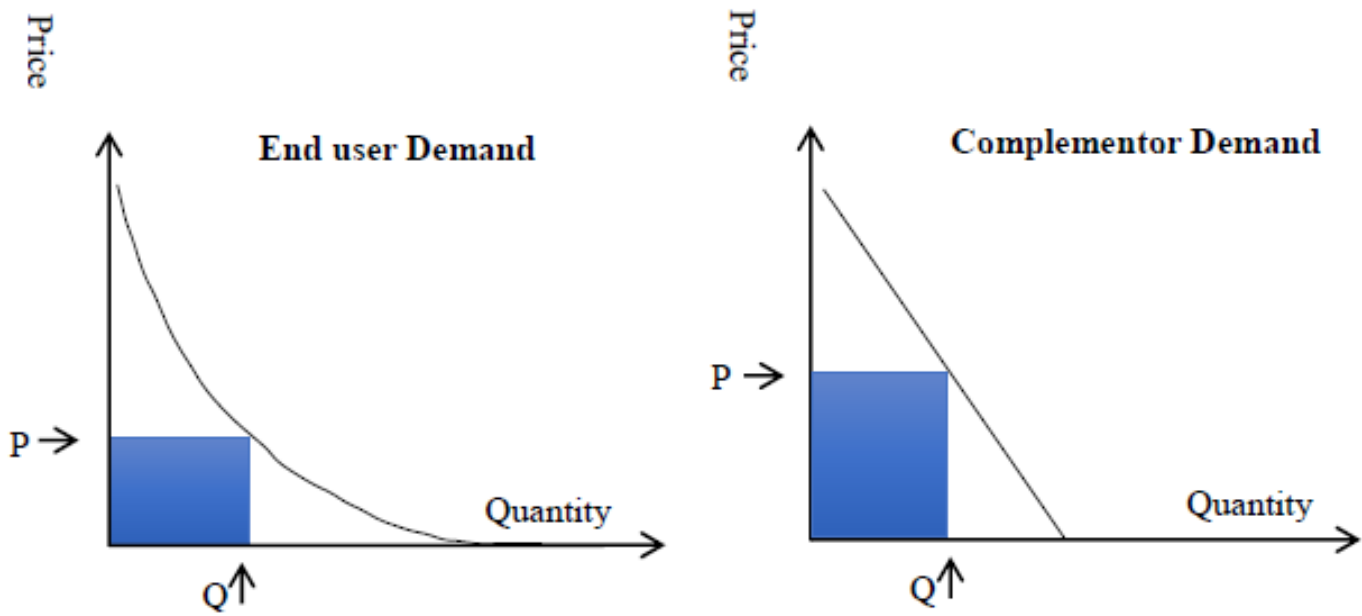

Source: Einsenmann, Parker and Alstyne, 2007

Figure 4: Traditional pricing model 


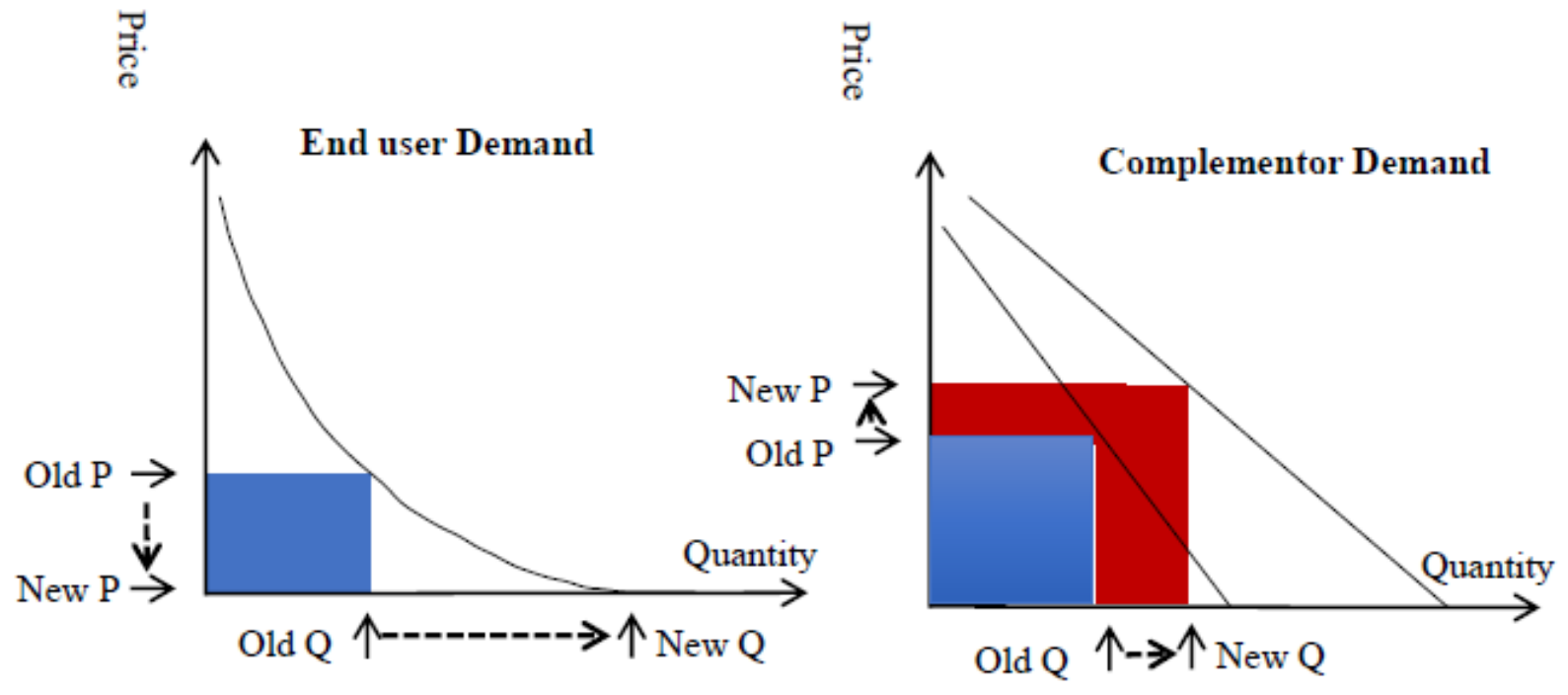

Source: Einsenmann, Parker and Alstyne, 2007

Figure 5: Two-sided market pricing model

The key to bind users onto the platform ecosystems is to improve the users' conversion costs. especially when the platform companies need to substantially subsidize a side, once the conversion cost is too low, the subsidy model is very likely to lead to disasters. Due to the diverse market groups that platforms service, there are considerable differences in the strategies to improve the conversion costs. Such as inducing customers to buy equipment, providing incentives to attract stationed, utilizing network effects to cultivate users, making soft mechanisms to improve the sense of belonging and so on.

Finally, the companies choosing platform model must have commercial awareness of multi-win cooperation and put the interest of others above one's own. Platform ecosystem development is not only the expansion of scale and the complex of organizational structure, but also the transformation of business philosophy from single win to win-win and multi-win. The success of the platform is not only the pursuit of profits maximization in a single market, but also openness and balance of the interests of all customers to complete platform companies' visions. Only when giving up some control and transferring enough profits, motivation of supplementary participants and outside support will be encouraged, and a steady stream of user traffic can be achieved.

Tiwana argues that the governance design of a platform may be examined from three angles: 1) decision rights partitioning, 2) control, and 3) proprietary versus shared ownership. Although platform ecosystems are similar to marketplaces in that they involve module authors, they are rarely transaction-oriented and necessitate extensive coordination, including platform architecture.

\section{Conclusion}

This research explores a major issue in the context of the two-sided markets setting: how can a platform company build an ecosystem for maximum its value under the new business operating model and Internet environment? It is specific to the platform ecosystem management strategies and future research directions which is worth exploring. As the theoretical exploration under the new situation, the expected contributions are mainly embodied in the following three aspects: 1) Combing the internal structure and evolution rules of the two-sided platform ecosystems. This research studies the platform theory from the perspective of ecosystem, integrating the commercial ecosystem theory, two-sided market theory and platform theory for the first time, integrates this concept aiming at the phenomenon of ecological cluster, and fill the blank in this area of research at home and abroad; 2) Studying two-sided platform ecosystem management strategies in depth. This research gives a

ISSN: 0010-8189 
multi-angle and multi-stage description of the two-sided platform management strategies from the perspective of ecosystems and the core companies, complementing the existing platform strategy literature; 3) Providing reference for the practice of platform business ecosystems. With the ecological development trend of platform model, this research makes the interaction and benefit mechanism of each ecological subject clear, which is of great significance to guide the platform ecosystem constructions and practical operations; and 4) Exploring future research prospects of platform ecosystems. Although the research results have been accumulated at present, but the research on the platforms is not yet mature, especially the research of the platform ecosystems involved need to be deepened. So, in the last part, we try to make a preliminary analysis on the future research trends and platform phenomena in order to promote the development of platform theory in the future.

Platform model and commercial ecosystems are considered as important strategic approaches nowadays. The ultimate goal of a platform is to create an ecosystem with growth potential and earning power. Only when properly managing the network relationships linked up by all the participants, having abilities to provide the best benefits and to meet the needs for each side of users, then the competitive advantage may arise. We estimate that in the next few decades, the platform model will invade most of the business fields, the platform ecosystems established in various industries will completely change the crowd behavior and industry models, and its impact will be further expanded. Therefore, it is necessary to carry out further in-depth research on the development trend and related theories of the platforms.

\section{References}

[1] Mcintyre, D.P, \& Srinivasan, A. (2016). Networks, platforms, and strategy: Emerging views and next steps. Strategic Management Journal, 38.

[2] Zhu, F., \& Iansiti, M. (2012). Entry into platform-based markets. Strategic Management Journal, 33, 88-106.

[3] Eisenmann, T.R. (2007). Platform-Mediated Networks: Definitions and Core Concepts. Harvard Business School note, 807-049.

[4] Jullien, B. (2001). Competing with Network Externalities and Price Competition. mimeo, Institute D' economic Industrielle (IDEI), France: Toulouse.

[5] Moore, J.F. (1993). Predators and prey: a new ecology of competition. Business Review, 71(3), 75-83.

[6] Rochet, J.C., \& Tirole, J. (2006). Two-sided markets: a progress report. RAND Journal of Economics, 37, 645-667.

[7] Evans, D.S., \& Schmalensee, R.(2007). The industrial organization of markets with two sided platforms. Competition Policy International, 3,151-179.

[8] Eisenmann, T.R. (2006). Internet companies' growth strategies: determinants of investment intensity and long-term performance. Strategic Management Journal, 27, 1183-1204.

[9] Shrivastava, S. (2012). Strategies for network platform evolution. Massachusetts Institute of Technology January, 2012.

[10] Cennamo, C., \& Santalo, S. (2013). Platform competition: strategic trade-offs in platform markets. Strategic Management Journal, 34, 1331-1350.

[11] Tiwana, A. (2008). Does interfirm modularity complement ignorance? A field study of software outsourcing alliances. Strategic Management Journal, 29(11), 1241-1252.

[12] Wheelwright, S.C., \& Clark, K.B. (1992). Creating project plans to focus product development. Harvard Business Review, 70(2), 70.

[13] Gawer, A., \& Cusumano, M.A. (2002). Platform Leadership: How Intel, Microsoft and Cisco Drive Industry Innovation. Boston: Harvard Business School Press.

[14] Gawer, A., \& Henderson, R. (2007). Platform owner entry and innovation in complementary markets: evidence from Intel. Journal of Economics and Management Strategy, 16, 1-34.

[15] Baldwin, C.Y., \& Woodard, C.J. (2009). The architecture of platforms: a unified view. In Platforms, Markets and Innovation, Gawer A (ed). Edward Elgar: Cheltenham, UK, 19-44. 
[16] Besanko, D., Dranove, D., \& Shanley, M. (1999). Economics of strategy. New York: John Wiley and Sons.

[17] Hoopes, D., Madsen, T., \& Walker, G. (2003). Why is there a resource-based view? Towards a theory of competitive heterogeneity. Strategic Management Journal, 24, 889-902.

[18] Peteraf, M., \& Barney, J. (2003). Unraveling the resource-based tangle. Managerial and Decision Economics, 24, 309-323.

[19] Adner, R., \& Kapoor, R. (2010). Value creation in innovation ecosystems: how the structure of technological interdependence affects firm performance in new technology generations. Strategic Management Journal, 31, 306-333.

[20] Li, Z, \& Wang, X.X. (2016). The research on mechanism of platform network effects and cross platform network effect. Science and Technology Progress and Policy, 10(20), 18-24.

[21] Katz, M.L., \& Shapiro, C. (1994). Systems competition and network effects. Journal of Economic Perspectives, 8, 93-115.

[22] Armstrong, M., \& Wright, J. (2007). Two-sided markets, competitive bottlenecks and exclusive contracts. Econom. Theory, 32(2), 353-380.

[23] Evans, D.S. (2003). Some empirical aspects of multi-sided platform industries. Review of Network Economics, 2, 191-209.

[24] Schilling, M.A. (2002). Technology success and failure in winner-take-all markets: the impact of learning orientation, timing, and network externalities. Academy of Management Journal, 45, 387-398.

[25] Boudreau, K.J. (2010). Open platform strategies and innovation: granting access vs. devolving control. Management Science, 56, 1849-1872.

[26] West, J. (2003). How open is open enough? Melding proprietary and open-source platform strategies. Research Policy, 32(7), 1259-1285.

[27] Rochet, J.C., \& Tirole, J. (2003). Platform competition in two-sided markets. Journal of the European Economic Association, 1, 990-1029.

[28] Wang, N. (2011). Research on pricing strategy of two-sided platform. Wuhan:Wuhan University.

[29] Choi, J. (1994). Network externality, compatibility choice, and planned obsolescence. Journal of Industrial Economics, 42, 167-182.

[30] Gawer, A. (2009). Platforms, Markets and Innovation. Northampton: Edward Elgar Publishing.

[31] Chen, W.R, \& Yu, Z.J. (2013). Platform Strategy: Business Model in Revolution. Beijing: China Citic Press.

[32] Zahra, S.A., \& Nambisan, S. (2012). Entrepreneurship and strategic thinking in business ecosystem. Business horizons, 55(3), 219-229.

[33] Iansiti, M., \& Levien, R. (2004). The Keystone Advantage: What the New Dynamics of Business Ecosystems Mean for Strategy, Innovation, and Sustainability. Boston: Harvard Business School Press.

[34] Gawer, A. (2014). Bridging differing perspectives on technological platforms: toward an integrative framework. Research Policy, 43, 1239-1249.

[35] Ceccagnoli, M., Forman, C., Huang, P., \& Wu, D.J. (2012). Cocreation of value in a platform ecosystem: the case of enterprise software. MIS Quarterly, 36, 263-290.

[36] Clements, M.T., \& Ohashi, H. (2005). Indirect network effects and the product cycle: video games in the U.S., 1994-2002. Journal of Industrial Economics, 53(4), 515-542.

[37] Parker, G., \& Van, Alstyne. M. (2005). Two-sided network effects: A theory of information product design. Management Science, 51, 1494-1504.

[38] Zhu, R.P. (2015). Analysis of dynamic and mechanism of co-evolution of business ecosystem based on platform perspective-Alibaba ecosystem as the case. Dalian: Dongbei University of Finance and Economics.

[39] Tushman, ML., \& Murmann, J.P. (1998). Dominant designs, technology cycles, and organizational outcomes. Research in Organizational Behavior, 20(1),53-86.

[40] Pil, F.K., \& Cohen, S.K. (2006). Modularity: Implications for imitation, innovation, and sustained advantage. Acad. Management Rev, 31(4), 995-1011. 
[41] Baldwin, C.Y., \& Clark, K.B. (2006). The architecture of participation: Does code architecture mitigate free riding in the open-source development model? Management Sci., 52(7), 1116-1127.

[42] Boudreau, K.J., \& Jeppesen, L.B. (2015). Unpaid crowd complementors: the platform network effect mirage. Strategic Management Journal, 36(12), 1761-1777.

[43] Bonardi, J., \& Durand, R. (2003). Managing network effects in high tech industries. Academy of Management Executive, 17, 40-52.

[44] Parker, G., \& Van, Alstyne. M. (2000). Information Complements, Substitutes, and Strategic Product Design. William Davidson Institute Working Papers.

[45] Normann, R., \& Ramírez, R. (1993). From value chain to value constellation: designing interactive strategy. Harvard Business Review, 71(4), 65-77.

[46] Farrell, J., \& Saloner, G. (1985). Standardization, compatibility, and innovation. RAND Journal of Economics, 16, 70-83.

[47] Hagiu, A., \& Wright, J. (2011). Multi-Sided Platforms. Harvard Business School. Cambridge: Harvard Business School.

[48] Eisenmann, T.R, \& Hagiu, A. (2007). Staging Two-sided Platforms. Harvard Business School Note, 808-004.

[49] Bakos, Y., \& Katsamakas, E. (2014). Design and ownership of two-sided networks: implications for Internet platforms. Journal of Management Information Systems, 25(2), 171-202.

[50] Suarez, F. (2005). Network effects revisited: the role of strong ties in technology selection. Academy of Management Journal, 48, 710-722.

[51] Swaminathan, A. (2001). Resource partitioning and the evolution of specialist organizations: the role of location and identity in the U.S. wine industry. Academy of Management Journal, 44, 1169-1185.

[52] Tiwana, A., Konsynski, B., \& Bush, A.A. (2010). Platform evolution: coevolution of platform architecture, governance, and environmental dynamics. Information Systems Research, 21(4), 675-687.

[53] McIntyre, D.P, \& Subramaniam, M. (2009). Strategy in network industries: a review and research agenda. Journal of Management, 35, 1494-1517.

[54] Venkatraman, N., \& Lee, C.H. (2004). Preferential linkage and network evolution: a conceptual model and empirical test in the U.S. Video game sector. Academy of Management Journal, 47, 876-892.

[55] Christensen, C.M., \& Bower, J.L. (1996). Customer power, strategic investment, and the failure of leading firms. Strategic Management Journal, 17(3), 197-218. 